\title{
DETECÇÃO AUTOMÁTICA DE FALHAS EM PRODUTOS SERIADOS UTILIZANDO FILTRO DE NOVIDADES
}

\section{AUTOMATIC FAILURE DETECTION OF SERIAL PRODUCTS USING NOVELTY FILTER}

\author{
Márcia Helena Veleda Moita* E-mail: mhvmoita@yahoo.com.br \\ Juliana Ferreguette Sena*E-mail: julianafsena@gmail.com \\ Ely Sena de Almeida* E-mail: ely pxe@yahoo.com.br \\ Rafael Postal* E-mail: faelpostal@gmail.com \\ *Universidade Federal do Amazonas (UFAM), Manaus, AM
}

\begin{abstract}
Resumo: O presente artigo apresenta uma ferramenta computacional que visa à detecção de falhas em produtos em série. $O$ trabalho inicia com uma breve descrição sobre a qualidade no processo produtivo e ressalta a importância da inspeção de falhas visando à qualidade do produto. Para ser realizada tal inspeção foram utilizadas técnicas de processamento digital de imagens e inteligência artificial. Este estudo deu-se em uma indústria que produz aparelhos celulares localizada no PIM Pólo Industrial de Manaus. A metodologia da ferramenta localiza áreas de possíveis defeitos e utiliza um processo onde, a partir de uma base de dados compostas de imagens padrões, a técnica do filtro de novidades é capaz de discernir, através do que lhe foi ensinado, regiões de falhas.
\end{abstract}

Palavras-chave: Ferramenta computacional. Inspeção. Falhas. Processamento digital de imagens. Filtro de novidades.

Abstract: The present paper focus on a computer tool that seeks the failure detection of serial products. This paper begins with a brief description about the quality on manufacturing process and points out the relevance of product inspection for detecting fails aiming the product's quality. For such inspection to be accomplished, was used Digital Image Processing Techniques and Artificial Intelligence. This research were done in a mobile phone industry located in the Manaus Industrial Polo - PIM. The tool's methodology localize the possible defect areas and uses a process in which, from a data base composed by pattern images, the Novelty Filter Technique is able to discern regions of failure through what it was instructed.

Keywords: Computational tools. Inspection. Failure. Digital image processing and novelty filter.

\section{INTRODUÇÃO}

O mercado está cada vez mais competitivo fazendo com que as empresas se tornem rigorosas na busca pela eficiência. As indústrias de hoje buscam adaptar novas tecnologias em suas linhas de produção para que atendam melhor as exigências do mercado consumidor.

Para Souza et al. (2012), os critérios de competitividade formam um conjunto de prioridades que a empresa deve adotar no seu contexto de participante no

Revista Produção Online, Florianópolis, SC, v.13, n. 3, p. 1143-1166, jul./set. 2013. 
mercado. Tais critérios incluem aspectos de custo, qualidade e flexibilidade, entre outros, e devem ser avaliados de forma integrada na busca de medidas que beneficiem a cadeia de forma equilibrada. Costa et al.,(2012) afirma que a competitividade imposta pelo mercado exige das organizações melhoria contínua de seus processos, sejam eles produtivos ou de apoio à produção (MARODIM et al., 2012).

Assim, estes aspectos incluem maior precisão na avaliação do produto, tanto na fase do processo quanto no produto final. A exemplo pode-se citar uma linha de produção em série responsável pelo envasamento de bebidas, onde é importante que todas as garrafas estejam com o nível correto de líquido ou, uma indústria farmacêutica responsável pelo empacotamento de remédios onde todos os pacotes devem estar com o número de medicamentos corretos, tornando assim, a qualidade um requisito indispensável para que uma empresa se mantenha no mercado.

Para ser realizado este tipo de controle de qualidade, métodos tradicionais de inspeção através de técnicos de diagnóstico se tornam cada vez mais ineficientes, portanto sendo de grande valia explorar novos métodos de inspeção que possibilitem a realização de tal tarefa de maneira confiável.

Sob este aspecto a metodologia de processamento digital de imagens e inteligência artificial tem se tornado um campo bastante interessante para o desenvolvimento de novas ferramentas de inspeção automática que auxiliariam dentro deste contexto. Os sistemas de visão computacional têm contribuído significativamente em diversas fases do ciclo produtivo de um produto, tais como, orientação de deslocamento de um robô, automatização de tarefas em células de manufatura, planejamento da produção e controle de qualidade, dentre outras (REDUK et al., 2001).

Existem vários métodos diferentes de se detectar falhas em produtos seriados. A maioria destes métodos é específico para um determinado tipo de produto. Já a inspeção através de visão de máquina é muito mais abrangente, pois pode ser utilizada em qualquer lugar onde a inspeção visual é válida.

Baseado neste argumento, o presente artigo tem como objetivo apresentar uma metodologia de detecção automática de falhas em produtos fabricados em série utilizando a combinação de duas grandes áreas que vêm sendo amplamente difundidas, o processamento digital de imagens e a inteligência artificial.

Revista Produção Online, Florianópolis, SC, v.13, n. 3, p. 1143-1166, jul./set. 2013. 


\section{REFERENCIAL TEÓRICO}

Esta seção apresenta uma breve descrição sobre a temática qualidade no processo produtivo e ressalta a importância da inspeção de falhas visando à qualidade do produto. Aborda também conceitos de processamento digital de imagens e de inteligência artificial.

\subsection{Qualidade no Processo Produtivo}

A década de 80 levou as empresas a se adaptarem em um ambiente com novos paradigmas e incluir em sua cultura conceitos e filosofias de trabalho como o just-in-time, produção em lotes únicos, melhoria contínua, qualidade total, entre outros. Este novo ambiente exige que as empresas estejam atentas ao mercado.

O cenário atual em que as empresas encontram o mercado consumidor é de alto nível de exigências, e a busca por redução de custo sem decréscimo da qualidade de seus produtos exige o olhar em outros componentes desse sistema produtivo que, a cada dia, torna-se mais enxuto. Segundo Coelho e Turroni (2008) a noção de qualidade mostra um processo de evolução desde sua introdução, visto que por volta de 1980 sua filosofia trazia a impressão de modismo. Entretanto, atualmente as práticas de qualidade apresentam-se como necessárias, se não essenciais para a sobrevivência competitiva das empresas.

Anteriormente, a qualidade era assegurada por meio de inspeção, segregando os defeitos antes que eles atingissem os consumidores, porém esse processo foi evoluindo chegando a usar técnicas de estatísticas robustas para não apenas identificar as falhas, mas tratar dos problemas.

No atual ambiente competitivo em que as empresas se encontram, estas precisam excluir ou, quando impossível, buscar melhorias nos processos ineficientes e trabalhos improdutivos que levam aos desperdícios. O conceito de desperdício segundo Wernke (2004) engloba os custos e despesas utilizados de forma não eficiente, ou seja, são consideradas como desperdícios todas as atividades que não agregam valor e resultam em gasto de tempo, dinheiro e recursos sem lucro.

Bornia (2002) afirma que o trabalho que não agrega valor, ou trabalho adicional, são as atividades que, apesar de não aumentarem o valor do produto, Revista Produção Online, Florianópolis, SC, v.13, n. 3, p. 1143-1166, jul./set. 2013. 
propiciam suporte para o trabalho efetivo. O mesmo autor conceitua o trabalho efetivo como aquele que compreende as atividades que, depois de realizadas, transformam o produto, ou seja, estes passam a valer mais do que antes.

De posse dos dois conceitos anteriormente citados, pode-se então afirmar com segurança que o tempo gasto no reparo de uma peça rejeitada é um desperdício no processo produtivo, diminuindo por sua vez, a confiabilidade do processo. Compreendem atividades que são necessárias à transformação de insumos, porém não agregam valor ao produto.

Segundo Robles Jr. e Bonelli (2008), os custos da qualidade são os investimentos de recursos aplicados em recursos ou serviços que visem incluir características de diferenciação do produto e satisfação plena do cliente, tanto no aspecto de praticidade de utilização quanto na questão do valor final para aquisição.

Esta premissa exige de todos os envolvidos no processo de produção de um bem ou serviço, uma postura que seja consciente da importância atribuída em atividades que tenham por objetivo eliminar o desperdício. Segundo os mesmos autores, os custos da não-qualidade surgem como um instrumento básico para as atividades de planejamento e tomada de decisão no que diz respeito à qualidade das organizações.

Por outro lado, Irianto (1995) afirma que o processo de inspeção de falhas visando à qualidade do produto é feita, na maioria das vezes, apenas no final da linha de produção. Esse procedimento faz com que o erro percorra todas as etapas do processo e o procedimento de retrabalho seja realizado no produto acabado, afetando dessa forma o output da linha.

Segundo o mesmo autor, um sistema de produção com $n$ estações de trabalho, conforme mostrado na Figura 1, possui intrinsecamente potencial para gerar variações em cada componente de saída de cada estação de trabalho. E a variação final que, dependendo das características do processo em análise, pode vir a ser a soma de todas as variações ocorridas, afetando diretamente, dessa forma, o output da linha de produção. 
Figura 1 - Sequência de $n$ estações de trabalho

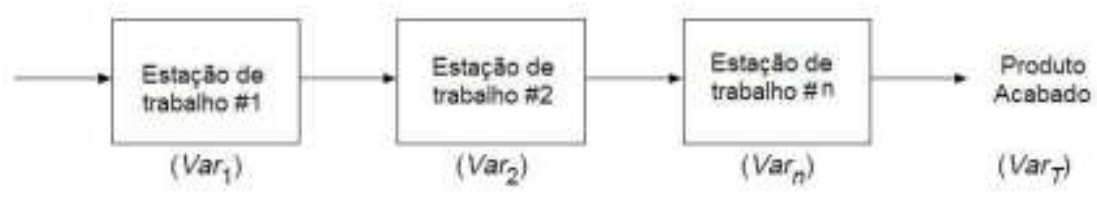

Fonte: Adaptado de Irianto (1995)

Bauer (1991) aponta uma solução para esse problema: instalar um procedimento de inspeção entre os processos e um monitorando das atividades após cada efetivação. Em adição a este método, Irianto (1995), propõe a inclusão da correção do erro antes que o item seja manufaturado pelos processos subseqüentes da linha de produção.

As atividades de processamento, inspeção e correção em cada etapa da manufatura provêem uma melhor qualidade dos produtos finais acabados, sem afetar de forma significativa o output da produção. Entretanto para isso torna-se necessária a aplicação de investimentos. A Figura 2 ilustra este processo onde as etapas de "processo" e "inspeção" podem ser realizadas por apenas um recurso e, a fase de "correção", por exigir conhecimento prévio de como realizar o reparo, deve ser realizada por outro recurso, destinado a esse fim, podendo ser chamado de "especialista".

Figura 2 - Estações de inspeção e retrabalho

(a)

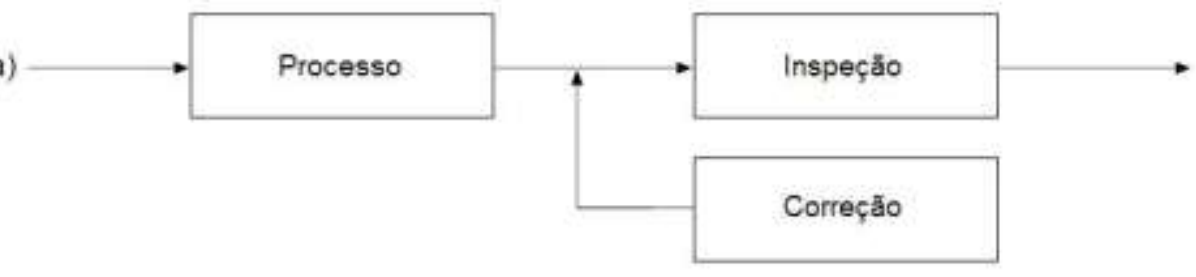

Fonte: Adaptado de Irianto (1995)

A fase de inspeção, especificamente, por ser realizada na maioria das vezes por um operador, apenas de forma visual, apresenta variação quando há troca de observador, chamada de variação inter-observador. Analisando a questão do ponto de vista de apenas um revisor, existe ainda a variação intra-observador, resultante da fadiga visual. Lembrando que se trata de um ser humano em questão que, após

Revista Produção Online, Florianópolis, SC, v.13, n. 3, p. 1143-1166, jul./set. 2013. 
várias investidas sobre determinado ponto, apresenta fadiga visual (SENA, 2007). As taxas de variação conseqüentes desse tipo de inspeção resultam em baixa eficiência da identificação de irregularidades quando se tem um padrão a ser seguido, impactando dessa forma, os índices dos indicadores da qualidade da cadeia produtiva.

Daveport (1994, apud Soares et al., 2006) afirma que a inovação de processos é um meio fundamental para a implementação de estratégias que visem a redução de custo, o aumento da velocidade de produção, a melhora do fluxo de trabalho, o aumento da qualidade do processo e a satisfação do cliente, tanto interno quando externo. E a técnica de tratamento digital de imagens figura como sendo uma alternativa a esses processos que se valem da visão humana, tais como identificação de falhas e diagnóstico de doenças, dentre outros.

\subsection{PDI e Al}

Devido à crescente automatização dos processos produtivos, busca-se tornar os sistemas computacionais e de robótica capazes de tornar automática a execução de tarefas complexas. No atual estágio de desenvolvimento da indústria brasileira, muitas destas tarefas complexas (que muitas vezes são repetitivas) são realizadas por operadores humanos (ORTH, 1998).

As novas tecnologias de visão computacional e processamento de imagens têm sido utilizadas com sucesso em muitas aplicações relevantes, principalmente nas áreas da astronomia, medicina, análise de impressões digitais, sensoriamento remoto, multimídia, entretenimento, reconhecimento de assinaturas, manufatura, robótica de manipuladores, robótica móvel, sistemas produtivos, entre outras.

O PDI - processamento digital de imagens nasceu do interesse de duas grandes áreas: melhoria de informação visual e o processamento visual para percepção automática através de visão de máquina. Uma das primeiras aplicações de técnicas de PDI da primeira área foi o melhoramento de imagens digitalizadas para jornais, onde as imagens eram transportadas através de um cabo submarino da cidade de Londres para Nova York (GONZALEZ, 2002).

Este tipo de transmissão chamado de sistema Bartlane, reduziu o tempo de transferência de dados das imagens de mais de uma semana para menos de três 
horas. Um equipamento especializado codificava as imagens para transmissão via cabo, as quais eram decodificadas no terminal receptor.

Os problemas iniciais enfrentados para tentar melhorar a qualidade visual das primeiras imagens digitais foram relacionados à seleção de procedimentos de impressão e a distribuição dos níveis de cinza. O método de impressão usado para obter a Figura 3 foi abandonado no final de 1921, para dar lugar ao método de reprodução fotográfica feita a partir de fitas perfuradas no terminal receptor. A Figura 4 ilustra uma imagem obtida através deste método, com qualidade superior a Figura 3 , tanto em resolução de profundidade quanto em resolução espacial.

Figura 3 - Imagem digital de 1921

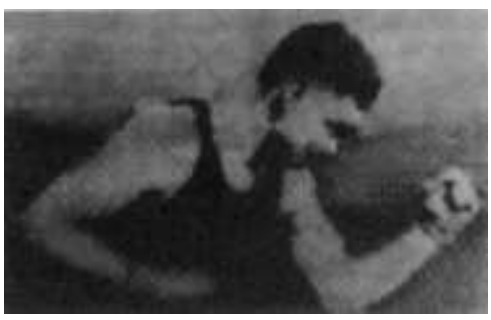

Fonte: Gonzalez (2002)

Figura 4 - Imagem digital de 1922

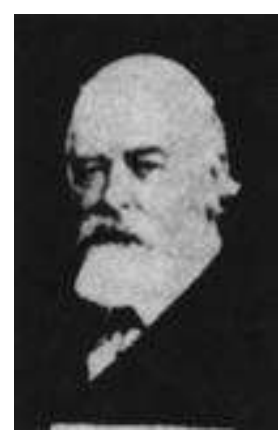

Fonte: Gonzalez (2002).

De 1924 até os dias de hoje, o PDI vem crescendo vigorosamente, sendo aplicado em diversas áreas da indústria e de diferentes formas de implementação. É certamente uma área em crescimento e as aplicações são, em sua maioria, de caráter interdisciplinar. Glenn e kirkland (2003) citam como exemplo a detecção de falhas em placas de circuito impresso através de imagens por infravermelho (IR), que vem a ser um método experimental que usa a vantagem do substrato de silício de ser transparente a certo tipo de comprimento de onda IR para verificar falhas nas 
trilhas dos circuitos impressos. Esta metodologia tem como objetivo diminuir o índice de falsos negativos (falhas falsas), pois detecta a maioria das falhas utilizando técnicas de equalização de histograma por especificação.

Técnicas de PDI também podem ser usadas para se fazer medição do tamanho de objetos, como a medição do diâmetro e espessura de cabos de isolamento através de filtros de detecção de bordas e operadores binários morfológicos com uma taxa de erro máxima de $0.01 \mathrm{~mm}$ (FAN et al., 2008).

A IA - inteligência artificial teve seu início após a segunda guerra mundial e atualmente abrange uma variedade de subcampos. Pode-se citar duas áreas de uso geral, como aprendizado e percepção, até áreas especificas como IA de jogos de vídeos-game e diagnósticos de doenças. A IA tem o objetivo de aperfeiçoar tarefas que envolvem o pensamento do homem, por esse motivo ela é fortemente aplicada em qualquer área do conhecimento humano (RUSSELL e NORVIG, 2003).

Segundo os mesmos autores, a IA é dividida em quatro grandes áreas de estudo, sendo duas destas áreas direcionadas ao pensamento humano: sistemas que pensam como seres humanos e sistemas que atuam como seres humanos. $E$, duas direcionadas a racionalidade: sistemas que pensam racionalmente e sistemas que atuam racionalmente.

Diversas são as aplicabilidades da IA. Percebe-se que as técnicas de IA vêm desempenhado papel importante na área de detecção de vírus de computador, diversas técnicas vêm sendo empregadas, tais como: técnicas de heurística, imunidade artificial, redes neurais, entre outras, de forma a aumentar a eficiência na localização destes vírus. Estas técnicas promovem o desenvolvimento de sistemas integrados com IA na detecção de vírus com maior robustez que, nos dias de hoje, é a principal tendência no desenvolvimento do campo de antivírus.

O Reconhecimento de padrões é uma área bastante interessante da IA, através dela é possível implantar algoritmos que reproduzam a capacidade humana de reconhecer objetos em máquinas. De acordo com Gonzalez (2002), o reconhecimento de padrões é formalmente definido como o processo pelo qual um padrão/sinal recebido é associado a uma classe dentro de um número finito de classes. Este é implementado como uma rede neural que passa por uma seção de treinamento no qual é apresentado um conjunto de padrões na entrada, onde a rede passa a assimilar estes padrões.

Revista Produção Online, Florianópolis, SC, v.13, n. 3, p. 1143-1166, jul./set. 2013. 
A rede neural é capaz de identificar a qual conjunto de padrões o novo padrão pertence pelo fato dela já ter extraído informação no momento do treinamento. Este tipo de rede neural tem uma natureza estatística, pois os padrões representam espaços multidimensionais, dividido em regiões associadas às classes. Como as regiões de decisão são determinadas pelo processo de treinamento, a construção das fronteiras também se torna estatística, uma vez que existe uma variação tanto nas classes como entre elas.

Naturalmente, toda essa discussão sobre aprendizado nos leva a pensar sobre memória, que é o processo de retenção de informações captadas pelos cinco sentidos humanos. Essas informações são armazenadas no cérebro em forma de lembranças que podem ser resgatadas posteriormente.

Existe um tipo de memória que é aplicada na área de redes neurais chamada de memória associativa, onde Pérez (1991) utiliza este tipo de memória para atingir alto grau de processamento.

O Filtro de Novidades é uma técnica introduzida por Kohonen e Oja (1976) e é considerada uma maneira de reconhecer padrões através da utilização de conceitos de memória associativa.

$\mathrm{O}$ rol de pesquisas que utilizaram este filtro é vasto. Dentre elas podemos citar: reconhecimento de voz em ambientes automobilísticos (BEH et al., 2009), detecção automática de lesões em cintilografias de mama (COSTA e MOURA, 1997) e Análise de movimentos (ARDIZZONE et al., 2009).

O objetivo do Filtro de Novidades é realçar as novidades relacionadas a padrões previamente instruídos. Segundo Ardizzone et al.(2009), o Filtro de Novidades é um filtro que realça as novidades que acontecem em um padrão de imagens que refletem a mesma cena.

Para melhor ilustrar, assume-se um caso hipotético onde um conjunto de peças é colocado em um produto em posições pré-determinadas. Muitas vezes, algumas dessas peças não são inseridas no produto, outras são trocadas de posição, podendo ser ocasionadas por desgastes de ferramentas, tendências em uma determinada máquina ou falta de insumos alimentados na mesma. Para ambas as situações é necessário fazer um diagnóstico e sinalizar a ocorrência de irregularidades no produto fabricado. 
Esse problema não pode ser resolvido através de uma técnica simples de subtração de imagens, pois existe certa variabilidade no posicionamento dos componentes no produto. Através do Filtro de Novidade e utilizando-se imagens de situações em que o produto final e seus acessórios estão acomodados de forma correta, pode-se construir uma base ortogonal de imagens (base). Essa base constitui a memória do sistema, assim, ao se submeter uma imagem $(x)$ do produto com uma parte (acessório) faltando ou fora do lugar ao Filtro de Novidades, teríamos duas informações distintas: em uma consta o registro de todas as características da imagem-teste que encontra respaldo (pode ser justificada) pela memória do filtro $(\hat{x})$; na outra consta o registro das características presentes na imagem-teste que não pode ser justificada pela memória do filtro $(\widetilde{x})$. A intensidade dessa última componente, denominada de NOVIDADE seria o sinalizador de anormalidade no produto, conforme ilustrado na Figura 5.

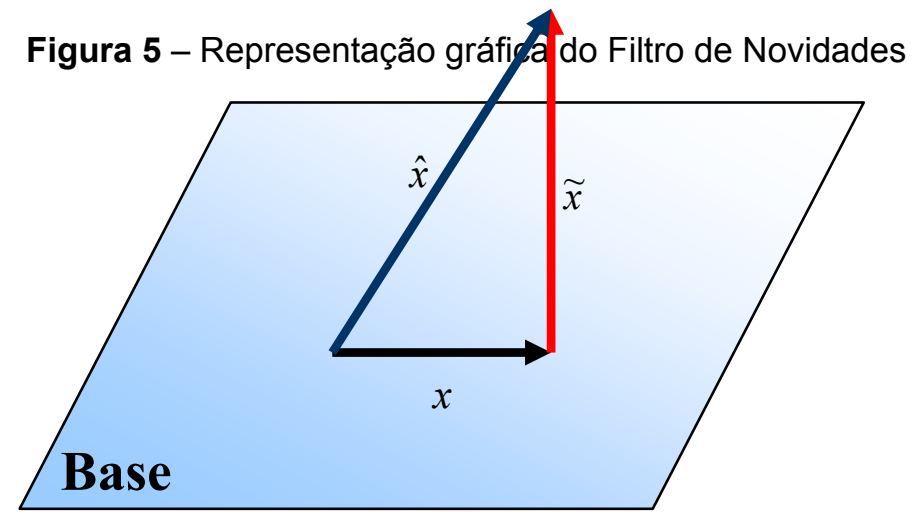

Fonte: os autores (2011)

$x \rightarrow$ o vetor de teste.

$\hat{x} \rightarrow$ a projeção ortogonal de $x$.

$\tilde{x} \rightarrow$ o complemento ortogonal de $x$.

Segundo Kassab e Alexandre (2009), o primeiro Filtro de Novidade introduzido por Kohonen e Oja (1976), é um algoritmo de ortogonalização que passa apenas pela componente de novidade de um vetor de entrada com relação a todos os dados de entrada previamente apresentados. Portanto, o filtro confia nas propriedades de operadores de projeção ortogonal.

Seguindo estas propriedades é possível decompor exclusivamente um vetor arbitrário $x \in R^{n}$ na soma de suas projeções ortogonais $\hat{x} \in \zeta \subset R^{n}$ e $\tilde{x} \perp \zeta$, sendo 
interessante observar que $\widetilde{x}$ pode ser entendido como a norma da distância entre $x$ e $\zeta$, e por isso o operador de projeção ortogonal pode direcionar o cálculo das projeções ortogonais de $x$.

Considere a matriz $X \in R^{n \times m}$ sendo $x_{i}$ seus vetores coluna, $X^{+}$sendo a matriz pseudo-inversa de $X$. Segundo provado por Penrose (1955) sempre existe uma única pseudo-inversa para qualquer matriz retangular.

O operador de projeção ortogonal que projeta $x \mathrm{em} \zeta$ é dado por $X . X^{+}$, logo:

$$
\hat{x}=X \cdot X^{+} \cdot x
$$

Analogamente, o operador de projeção ortogonal que projeta $x$ em $\zeta$ é dado por $\left(I-X . X^{+}\right)$, então fica: $\widetilde{x}=\left(I-X . X^{+}\right) x$, sendo $I$ a matriz identidade de $X$.

O fato é que quando se trata de imagens, o cálculo do operador de projeção ortogonal exige um grande esforço computacional dependendo do tamanho das imagens e de quantas imagens serão necessárias para formar a base, pois cada coluna da matriz $X$ representa um padrão de referência (imagem da base).

Portanto, para resolver o problema acima, pode ser escolhida a ortogonalização de Gram-Schmidt para se obter a projeção ortogonal $\widetilde{x}$,que vem a ser a NOVIDADE.

No processo de ortogonalização de Gram-Schmidt, uma base $\left\{v_{1}, v_{2}, \ldots, v_{p}\right\}$ é substituída por outra ortogonal $\left\{u_{1}, u_{2}, \ldots, u_{p}\right\}$, com a característica adicional de que, para cada $i$, existem $\alpha$ 's tais que $u_{i}=v_{i}-\sum_{j=1}^{i-1} \alpha_{j} v_{j}$.

\section{DETECÇÃO DE FALHAS EM UM PROCESSO PRODUTIVO UTILIZANDO O FILTRO DE NOVIDADE}

Esta seção busca apresentar uma breve descrição do processo produtivo em estudo e do controle de qualidade desse processo. A problemática norteadora do estudo e a ferramenta proposta na pesquisa, também são apresentadas nessa seção. 


\subsection{Descrição do Processo Produtivo}

Este trabalho foi desenvolvido em uma indústria que produz aparelhos celulares localizada no PIM - Pólo Industrial de Manaus. As características do processo produtivo da Empresa baseiam-se em uma linha de produção que no início do processo utiliza tecnologia SMT - surface mount technology. Esta tecnologia utiliza máquinas de montagem de componentes de tamanho milimétricos em superfície conhecidos como SMD - surface mount device, seguidas por estágios de inserção do software, calibração, montagem, testes de funcionalidade, customização e, por fim, embalagem. A Figura 6 fornece uma visualização apenas do processo de fabricação, especificando o nome dado a cada etapa.

Figura 6 - Fluxograma do Processo Produtivo

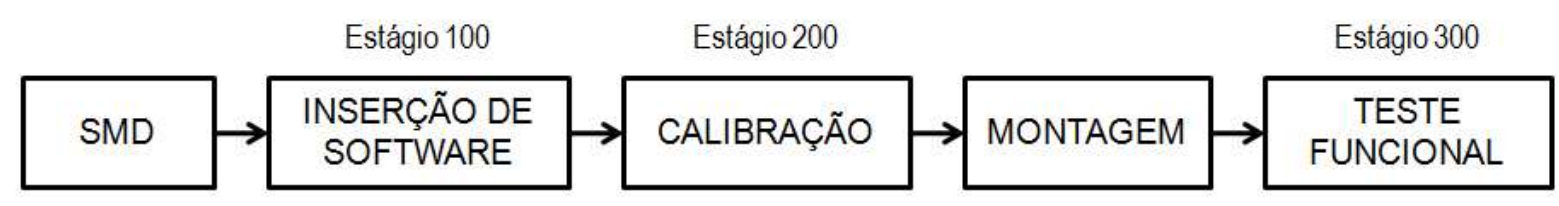

Fonte: os autores (2011)

O processo inicial é constituído por máquinas com funções distintas, tais como: montagem de componentes com e sem precisão apurada, inserção de pasta de solda e forno para refusão da solda. Não existe verificação quanto ao funcionamento do produto fabricado nesta etapa do processo. Entretanto, em linhas que apresentam um índice elevado de erros no que diz respeito à posição de componentes na placa, existe a figura do "Revisor", cuja função é a de validar ou corrigir as placas que apresentam alguma irregularidade.

As placas aprovadas são encaminhadas ao Estágio 100, responsável pela inserção do software de funcionamento do produto, agora chamado de transceptor, que também define um número de rastreamento. $O$ rastreamento permite a coleta de dados do item ao longo de todo o processo da manufatura. A partir deste estágio, surge o "Técnico de Diagnóstico", pessoa responsável pelas informações de falhas colocadas no banco de dados que ocorrem na fabricação dos celulares assim como, responsável pelo monitoramento do processo.

O monitoramento de um ou mais processos envolve os Técnicos de Diagnósticos que, por conseguinte, ficam com a incumbência de detectar a área 
defeituosa e efetuar o reparo ou o retrabalho quando possível, ou tornar sucata o produto que não possuir condições de reparo.

A alocação destes técnicos dentro do processo pode ser visualizada na Figura 7. Os colaboradores estão dispostos em quatro bancadas, sendo que duas são destinadas para análise das falhas provenientes do estágio 100 e 200 e as restantes para o estágio 300 .

Figura 7 - Disposição dos Técnicos de Diagnóstico

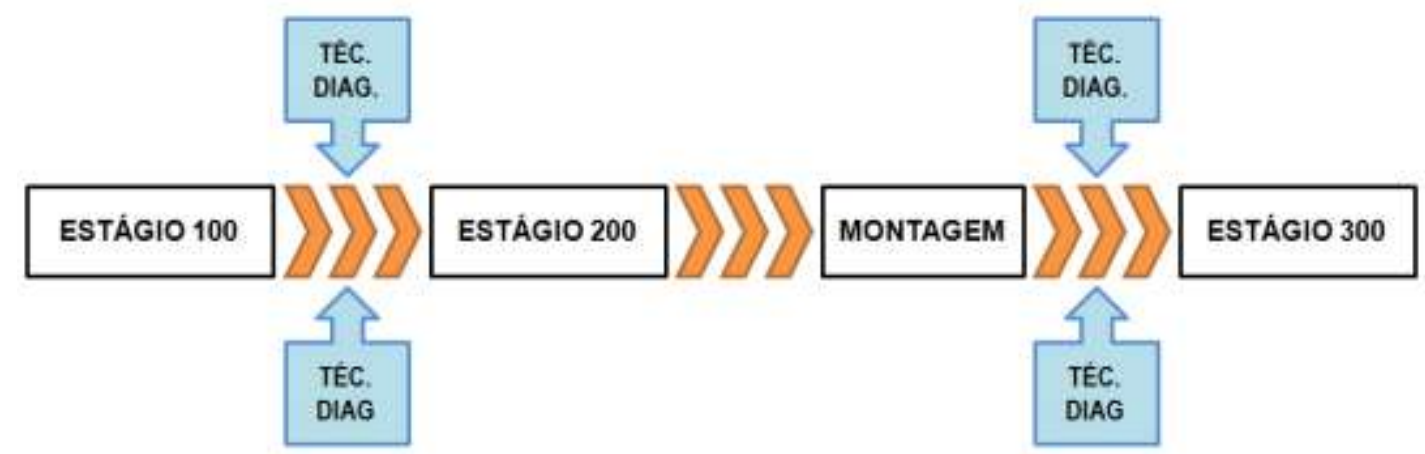

Fonte: os autores (2011)

As placas que não apresentam falhas no processo de inserção de software seguem para o Estágio 200, onde é feita a calibração do transceptor de acordo com as normas padrões adotadas pelos institutos certificadores de transmissão em rádio freqüência. Como este estágio trata de ajustes de freqüência, este pode vir a gerar perdas ou falhas falsas em todo o processo produtivo posterior a este, caso este ajuste não tenha se dado de forma efetiva.

O Estágio 300 tem como função principal validar a montagem feita pelos operadores assim como verificar os recursos oferecidos pelo telefone celular ao usuário final, diferentes da sua função básica, testada no estágio anterior. Este estágio se mostra propício à falha devido à interação humana no estágio de montagem e apresenta o maior índice de falhas do processo. Ao fim deste processo, o aparelho celular é transferido para o setor de operação e distribuição onde o produto será customizado de acordo com o cliente. 


\subsection{Controle de Qualidade do Processo}

Devido à forte concorrência no setor de aparelhos eletrônicos e as exigências dos consumidores, a Empresa acredita que para manter-se no mercado, bem como aumentar sua participação, a qualidade é um requisito essencial. Sendo assim, os itens produzidos passam por um controle de qualidade extremamente rigoroso.

No começo do ano de 2006, devido às grandes perdas de produtividade decorrente do aumento excessivo de falhas no processo produtivo, a Empresa adotou um processo de monitoramento. Esta mudança veio acompanhada de uma nova visão gerencial que se instalava na empresa em âmbito global. Manaus como sendo uma das empresas que necessitava de ajustes, devido o alto nível de rejeito, criou um programa intenso de monitoramento do processo envolvendo três fases até chegar ao que se chama hoje de monitoramento do MFR - Manufacturing Failure Rate.

A etapa inicial desse processo se deu pela a formação de equipes técnicas em turnos que trabalhavam diretamente no reparo dos produtos rejeitados, diagnosticando e catalogando os problemas e as causas mais constantes. A segunda etapa deste processo foi a orientação massiva das entradas dos diagnósticos de forma correta para a criação do banco de dados. Por fim a criação de um acompanhamento semanal, em nível gerencial, com os lideres de cada setor e área dentro da Empresa a fim de validar as ações e propor soluções para as melhorias do processo, reduzindo o tempo de reação na correção de falhas diárias.

Assim, o MFR é um indicador utilizado para fazer o acompanhamento da qualidade do processo. O monitoramento deste processo utiliza os dados provenientes do banco de dados montado com as informações obtidas pelo número de rastreamento fornecido à placa no Estágio 100 (Figura 7). O cálculo do MFR utiliza as unidades que não foram aprovadas em algum ponto da produção e as relaciona com o total fabricado naquele mesmo ponto (MÄENTEKA, 2008). O cálculo do MFR geral é mostrado pela Equação I.

MFR = Unidades reprovadas / (Unidades aprovadas + Unidades reprovadas)

(Equação I)

Para Pulkkinen (2005), o MFR é uma definição recentemente introduzida que mostra o rendimento do produto em um processo produtivo. O MFR pode ser visto Revista Produção Online, Florianópolis, SC, v.13, n. 3, p. 1143-1166, jul./set. 2013. 
como uma medida que indica a capacidade do processo industrial para produzir qualidade.

Para o autor supracitado, reduzir o MFR significa obter ganhos em relação ao rendimento já que o número de unidades perdidas será menor.

Como foi mencionado anteriormente, as indústrias visam sempre a redução de desperdícios e o aumento na qualidade. Estes, por sua vez, influenciam diretamente em custos desnecessários para a empresa. E de acordo com Juran (1993) a qualidade está envolvida diretamente no controle do processo.

O MFR é uma forma, dentre outras, de se medir esta qualidade, e com isso posteriormente é possível controlar um processo e monitorar o desenvolvimento de um ou mais processos através deste indicador.

Normalmente o ponto inicial onde é feita a coleta do MFR se localiza no primeiro estágio do processo de manufatura. Isto se dá, pois seguindo o cálculo do MFR composto, fica bem mais interessante que o defeito seja localizado o quanto antes, podendo assim evitar defeitos em outros pontos de coleta do MFR que possam vir a ser provenientes de um defeito inicial e, com isso, é possível reduzir este índice.

O MFR pode ser visto como um artifício utilizado para enxergar quais as causas ou processos que geram os defeitos.

\subsection{Descrição da Problemática}

Fazendo uma síntese do MFR da fábrica em estudo, classificando-o por áreas causadoras de defeitos é possível analisar os fatores que contribuíram para o aumento e redução de defeitos, como mostrado na Figura 8. 
Figura 8- MFR por natureza das falhas

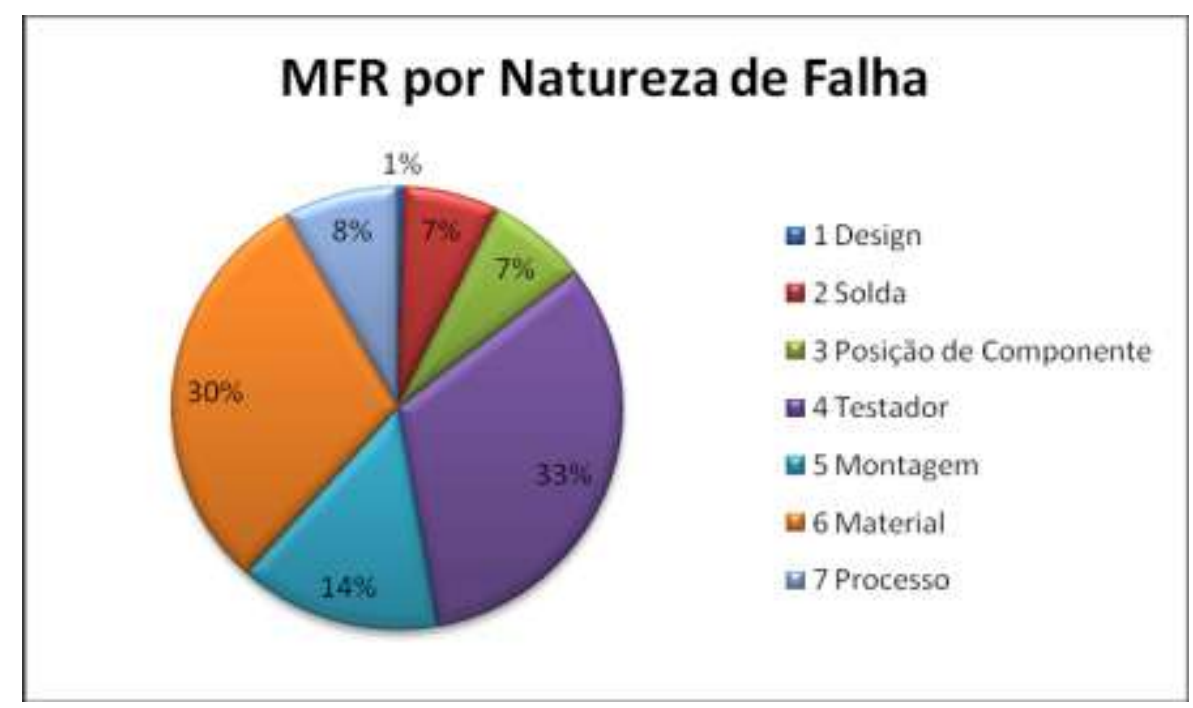

Fonte: os autores (2011)

Analisando a Figura 8, por exemplo, observa-se que o MFR foi afetado em $7 \%$ devido a falhas geradas por falta de componentes ou alocação incorreta (deslocamento) dos mesmos, caracterizada pela área "Posição de Componente". Neste caso, poder-se-ia reduzir o MFR em até 7\% com o auxílio de ferramentas que detectasse automaticamente esses defeitos. Atualmente, a técnica utilizada na Empresa é baseada no diagnóstico visual, ou seja, os defeitos são localizados por um operador humano, de forma morosa e cansativa. Destaca-se também, que com auxílio da ferramenta automática de detecção de falhas, essa falha seria detectada no primeiro acontecimento da falta de um componente, no estágio onde o problema ocorreu, e com isso seria possível rever a causa raiz do problema, que poderia ser a falta de alimentação de matéria-prima da máquina ou algum outro problema ocorrido e, logo após, corrigir-se-ia o problema.

Assim, analisando criticamente a Figura 8, conclui-se que uma ferramenta capaz de detectar e indicar automaticamente o local da falha pode, de certa forma, auxiliar para que o técnico aponte o defeito mais rapidamente e garanta que a falha não seja detectada em outro estágio que não seja o gerador do defeito, e com isso é possível reduzir o MFR referente aquele tipo de defeito. 


\subsection{A Ferramenta Proposta}

A inspeção e tratamento das falhas é uma atividade do processo situada na transição entre dois estágios, uma vez que é de vital importância que as placas não passem com defeito para o próximo estágio.

Se uma inspeção utilizando o Filtro de Novidades for aplicada neste processo produtivo conforme a Figura 9, o "Revisor" e o "Técnico de Diagnóstico" não serão substituídos. Porém, este processo afetaria positivamente o trabalho por eles realizado na medida em que garante maior precisão quando na identificação e redução do tempo despendido no diagnóstico da falha de caráter visual.

Figura 9 - Disposição dos Técnicos de Diagnóstico

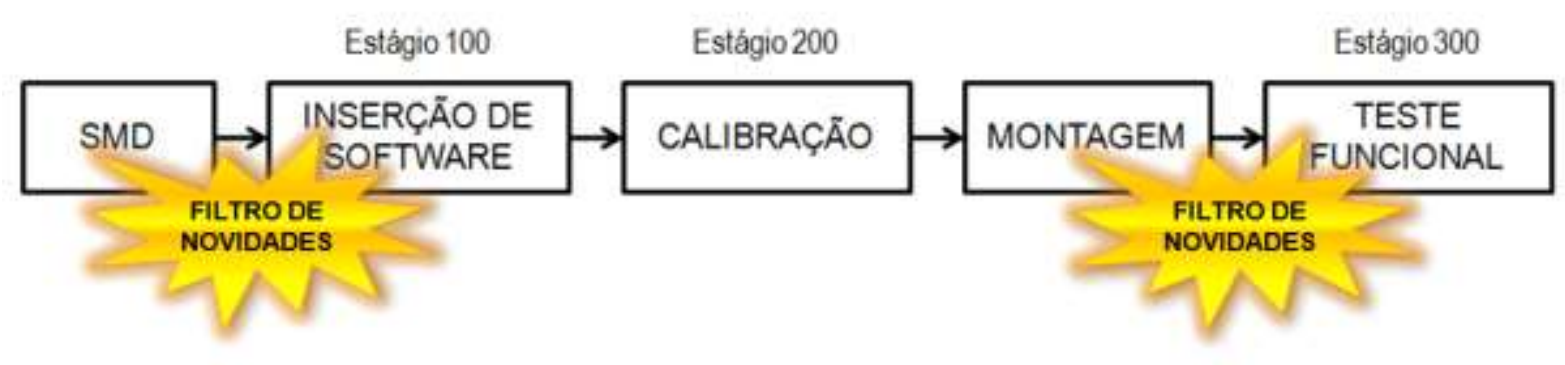

Fonte: os autores (2011)

Para o "Técnico de Diagnóstico" a decisão se tornará embasada pelas informações fornecidas pelo Filtro de Novidades que irá fornecer a imagem das prováveis regiões de falhas nas placas em análise.

Para exemplificar o funcionamento da ferramenta proposta pelo artigo, imagina-se inserir três (03) imagens padrões $\left\{v_{1}, v_{2}, v_{3}\right\}$ na base de um sistema de detecção de falhas em placa de circuito integrado situada no estágio inicial do processo produtivo de aparelhos celulares. Essas imagens constituem a condição de normalidade da placa.

Como referência, utilizamos a Imagem Padrão $1\left(v_{1}\right)$, de forma que $u_{1}=v_{1}$, conforme Figura 10. 
Figura 10 - Imagem Padrão $1\left(v_{1}\right)$ representada pela componente de intensidade

\begin{tabular}{|c:c:c:c:c|}
\hline 130 & 110 & 128 & 133 & 138 \\
\hdashline 182 & 153 & 147 & 143 & 126 \\
\hdashline 115 & 90 & 96 & 100 & 97 \\
\hdashline 116 & 101 & 133 & 138 & 146 \\
\hdashline 160 & 136 & 144 & 128 & 127 \\
\hdashline 105 & 96 & 95 & 96 & 92 \\
\hdashline 93 & 92 & 85 & 90 & 90 \\
\hdashline 103 & 104 & 100 & 96 & 104 \\
\hdashline 77 & 81 & 71 & 65 & 66 \\
\hdashline 37 & 36 & 40 & 49 & 45 \\
\hdashline 254 & 253 & 251 & 253 & 255 \\
\hline
\end{tabular}

Fonte: os autores (2011)

A partir de $u_{1}$ (primeiro vetor imagem que compõe a base), pode-se ortogonalizar as outras imagens que irão fazer parte da base, conforme processo de ortogonalização anteriormente descrito.

$$
\begin{gathered}
u_{2}=v_{2}-\alpha v_{1} \\
u_{3}=v_{3}-\beta v_{1}-\lambda v_{2}
\end{gathered}
$$

Onde: $\alpha=\frac{\left\langle v_{2}, u_{1}\right\rangle}{\left\langle u_{1}, u_{1}\right\rangle}, \quad \beta=\frac{\left\langle v_{3}, u_{1}\right\rangle}{\left\langle u_{1}, u_{1}\right\rangle}$ e $\lambda=\frac{\left\langle v_{3}, u_{2}\right\rangle}{\left\langle u_{2}, u_{2}\right\rangle}$ 
Figura 11- (a) Imagem Padrão $2\left(v_{2}\right)$ representada pela componente de intensidade e (b) Imagem 2 ortogonalizada $\left(u_{2}\right)$

\begin{tabular}{|c:c:c:c:c|}
\hline 106 & 92 & 114 & 115 & 117 \\
\hdashline 160 & 141 & 153 & 149 & 147 \\
\hdashline 140 & 114 & 113 & 103 & 106 \\
\hdashline 97 & 93 & 112 & 115 & 117 \\
\hdashline 141 & 142 & 158 & 153 & 138 \\
\hdashline 117 & 109 & 108 & 101 & 92 \\
\hdashline 94 & 88 & 92 & 96 & 92 \\
\hdashline 95 & 88 & 90 & 95 & 90 \\
\hdashline 106 & 96 & 100 & 99 & 91 \\
\hdashline 30 & 39 & 30 & 31 & 25 \\
\hdashline 188 & 191 & 201 & 210 & 225 \\
\hline
\end{tabular}

\begin{tabular}{|c:c:c:c:c|}
\hline-14 & -10 & -4 & -8 & -10 \\
\hdashline-8 & 0 & 17 & 17 & 31 \\
\hdashline 34 & 31 & 24 & 11 & 16 \\
\hdashline-10 & 0 & -11 & -12 & -18 \\
\hdashline-7 & 16 & 25 & 35 & 21 \\
\hdashline 20 & 20 & 20 & 12 & 7 \\
\hdashline 8 & 3 & 14 & 13 & 9 \\
\hdashline 0 & -8 & -2 & 6 & -6 \\
\hdashline 35 & 21 & 34 & 39 & 30 \\
\hdashline-4 & 6 & -7 & -14 & -17 \\
\hdashline-46 & -43 & -31 & -24 & -10 \\
\hline
\end{tabular}

(a)

(b)

Fonte: os autores (2011)

Figura 12 - (a) Imagem Padrão $3\left(v_{3}\right)$ representada pela componente de intensidade e (b) Imagem 3 ortogonalizada $\left(u_{3}\right)$

\begin{tabular}{|c|c:c|c|c|}
\hline 90 & 83 & 93 & 93 & 98 \\
\hdashline 150 & 135 & 145 & 148 & 141 \\
\hdashline 148 & 121 & 118 & 115 & 108 \\
\hdashline 92 & 81 & 93 & 100 & 101 \\
\hdashline 133 & 124 & 136 & 139 & 133 \\
\hdashline 138 & 118 & 114 & 112 & 106 \\
\hdashline 81 & 76 & 79 & 88 & 93 \\
\hdashline 95 & 94 & 87 & 78 & 81 \\
\hdashline 99 & 92 & 95 & 92 & 88 \\
\hdashline 48 & 52 & 42 & 43 & 39 \\
\hdashline 106 & 116 & 130 & 147 & 157 \\
\hline
\end{tabular}

\begin{tabular}{|c:c:c:c:c|}
\hline 8 & 10 & -2 & -1 & 4 \\
\hdashline 18 & 14 & 3 & 9 & -5 \\
\hdashline 6 & 3 & 5 & 20 & 6 \\
\hdashline 15 & 1 & 4 & 9 & 12 \\
\hdashline 16 & -8 & -16 & -15 & 1 \\
\hdashline 25 & 11 & 8 & 17 & 23 \\
\hdashline-5 & -1 & -9 & -3 & 8 \\
\hdashline 14 & 24 & 11 & -8 & 8 \\
\hdashline-15 & -4 & -13 & -18 & -10 \\
\hdashline 25 & 15 & 21 & 26 & 28 \\
\hdashline-25 & -20 & -23 & -18 & -29 \\
\hline
\end{tabular}

(a)

(b)

Fonte: os autores (2011)

Revista Produção Online, Florianópolis, SC, v.13, n. 3, p. 1143-1166, jul./set. 2013. 
A simulação da Imagem de Teste é apenas mais um passo na ortogonalização, porém esta imagem não é colocada na base.

Figura 13- (a) Imagem de Teste $\left(v_{T}\right)$ representada pela componente de intensidade e (b) Imagem de Teste ortogonalizada $\left(u_{T}\right)$

\begin{tabular}{|c:c:c:c:c|}
\hline 105 & 109 & 115 & 138 & 170 \\
\hdashline 125 & 114 & 107 & 104 & 108 \\
\hdashline 133 & 133 & 145 & 150 & 139 \\
\hdashline 98 & 100 & 115 & 138 & 154 \\
\hdashline 120 & 104 & 102 & 105 & 100 \\
\hdashline 120 & 112 & 135 & 137 & 109 \\
\hdashline 97 & 100 & 125 & 133 & 125 \\
\hdashline 97 & 100 & 94 & 89 & 97 \\
\hdashline 106 & 105 & 94 & 110 & 94 \\
\hdashline 90 & 97 & 112 & 112 & 107 \\
\hdashline 223 & 223 & 228 & 71 & 81 \\
\hline
\end{tabular}

(a)

\begin{tabular}{|c:c:c:c:c|}
\hline-12 & 4 & 8 & 27 & 49 \\
\hdashline-57 & -42 & -40 & -49 & -19 \\
\hdashline-3 & 26 & 34 & 25 & 31 \\
\hdashline-20 & 9 & -1 & 11 & 20 \\
\hdashline-41 & -16 & -21 & -13 & -30 \\
\hdashline-24 & -5 & 24 & 17 & -11 \\
\hdashline 16 & 18 & 52 & 48 & 26 \\
\hdashline-14 & -21 & -9 & 10 & -2 \\
\hdashline 33 & 23 & 25 & 50 & 27 \\
\hdashline 24 & 39 & 51 & 42 & 38 \\
\hdashline 69 & 60 & 61 & -110 & -95 \\
\hline
\end{tabular}

(b)

Fonte: os autores (2011)

A saída desta ortogonalização, a imagem teste ortogonalizada $\left(u_{T}\right)$, retrata o quanto a intensidade dos pixels das imagens de teste não conseguiram ser explicadas pela base. Após este passo é necessário a aplicação de um limiar, que neste exemplo definimos como $x_{1}=-30$ e $x_{2}=30$. Para segmentar as novidades $(x)$ usa-se a equação $x_{1}>x>x_{2}$. Todos os pixels que satisfazem esta equação representam as novidades (regiões da imagem contendo possíveis defeitos), ilustrados na Figura 13(b) em cor cinza.

A Figura 14 ilustra o exemplo prático do Filtro de Novidade, onde a região em vermelho retrata os locais de defeito, que neste caso é a falta de uma ilha para solda e a outra uma falha devido ao deslocamento de posição. 
Figura 14 - (a) Condição de normalidade e (b) Imagem teste submetida ao filtro com defeitos localizados em vermelho
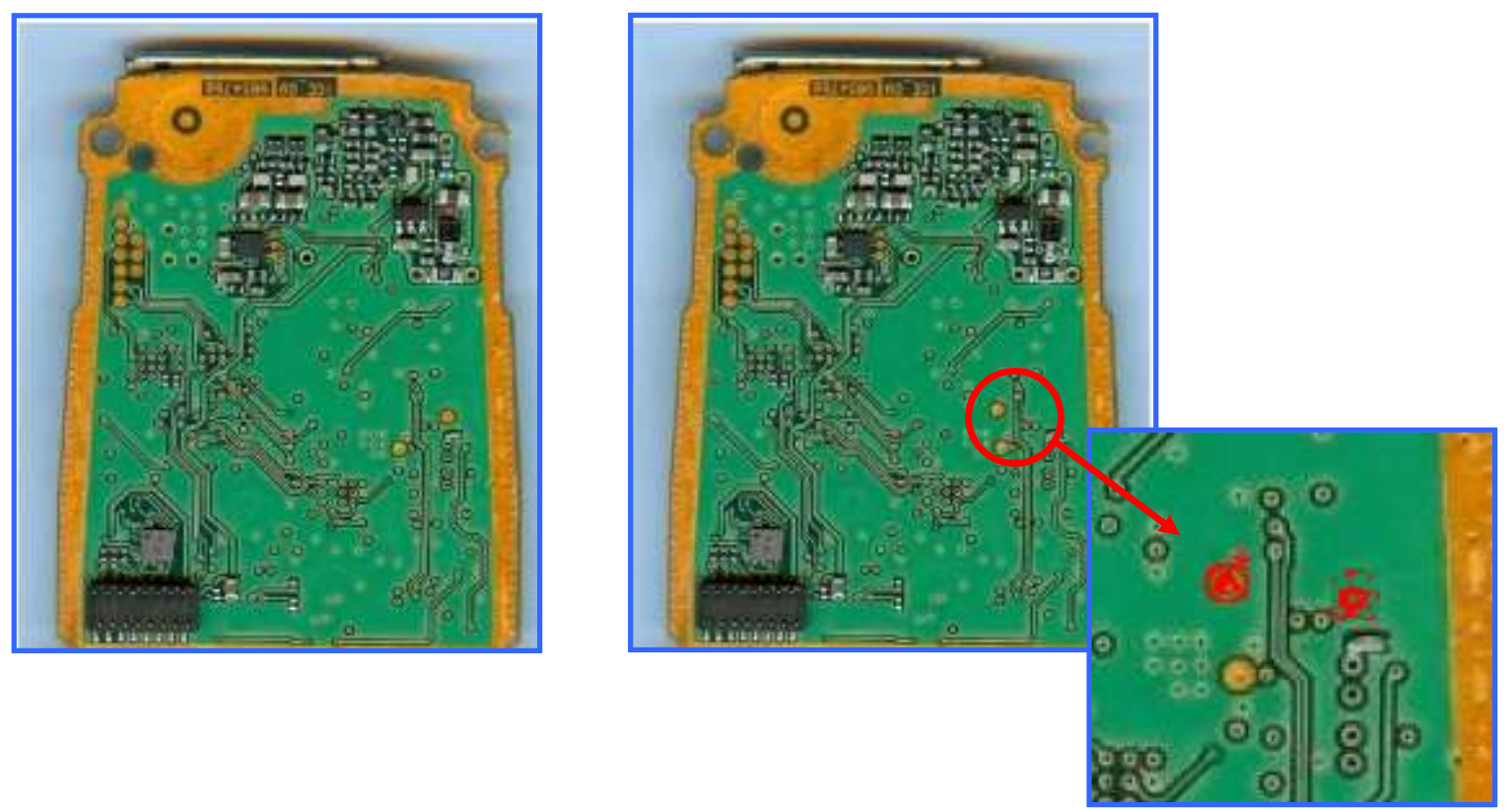

\section{CONSIDERAÇÕES FINAIS}

Este trabalho apresenta uma proposta de detecção de defeitos para produtos com características específicas onde os componentes de um produto têm posições pré-determinadas e, a falta ou alocação incorreta de um componente representa o defeito.

Tal proposta consiste na utilização de técnicas de reconhecimento de padrões utilizando memória associativa - o Filtro de Novidades. Esta técnica de reconhecimento de padrões pode ser implementada por diversas formas: Ortogonalização de Gram-Schimdt, Matriz Pseudo-Inversa e Redes Neurais.

Não se utilizou a implementação desta técnica através de Redes Neurais, pois redes tornaria o processo de auxílio à detecção de defeitos inflexível, uma vez que ao ser mudado o produto em inspeção, haveria a necessidade de treinamento de uma nova Rede Neural, exigindo assim o conhecimento de um especialista que seria o responsável por mudar a topografia da rede, estabelecer novos pesos e outras configurações necessárias para o treinamento e convergência da rede, e outros testes para garantir a eficiência do processo de inspeção.

A técnica do Filtro de Novidades implementada através de Matriz PseudoInversa demandou de um processamento muito alto, tornando o método lento e

Revista Produção Online, Florianópolis, SC, v.13, n. 3, p. 1143-1166, jul./set. 2013. 
inviável para auxiliar a detecção de defeitos em produtos em série, devido à necessidade de uma sinalização mais rápida das possíveis localidades dos defeitos.

O método escolhido para implementação do Filtro de Novidades neste trabalho foi a ortogonalização de Gram-Schmidt, pois se mostrou um método de fácil utilização onde o único requisito seria o de ter um técnico que conheça quais as condições normais de um determinado produto, podendo assim escolher as imagens que servirão como padrão para análise de defeitos.

Para automatizar o método de escolha do limiar que deve ser aplicado nas imagens e obter resultados de sensibilidade e especificidade do método, faz-se necessário um estudo aprofundado e a execução de testes em diversos produtos diferentes.

As indústrias buscam sempre a redução de desperdícios e o aumento na qualidade e estes, por sua vez, influenciam diretamente em custos desnecessários para a empresa. Apesar do processo de monitoramente, adotado pela Empresa em estudo, ser muito eficaz quando a se tratar do acompanhamento do processo produtivo, verificou-se que a implementação de ferramentas como essa apresentada na pesquisa, mostra-se viável e pertinente.

\section{REFERÊNCIAS}

ARDIZZONE, E. et al. Motion analysis using the novelty filter. 2009.

BAUER, J. A.; BROWNE, R. B; DUGGAN, J. Shop floor control systems. Chapam e Hall, London, 1991.

BEH, J.; BARAN, R.; e KO, H. Dual channel based speech enhancement using novelty filter for robust speech recognition in automobile environment. IEEE. 2009.

BORNIA, A. C. Análise gerencial de custos: aplicação em empresas modernas. Porto Alegre: Bookman, 2002.

COELHO, A. F. C; TURRONI, J. B. Validação de instrumentos para medição de práticas de gestão da qualidade em empresas certificadas pela ISO9001 e sua aplicação em Itajaúba. Pesquisa e Desenvolvimento em Engenharia de Produção, n.8, p.78-92, 2008.

COSTA, A. H., LIMA, J. F. G., GOMES, M: L. B. Redução do tempo de setup na produção de botas de pvc através da técnica TRF Revista Produção Online. Florianópolis, v.12, n. 1, p. 119-132, jan./mar. 2012. 
COSTA, M. G. F. ; MOURA JR, L. A. Detecção automática de lesões em cintilografias de mama com mibi-99mtc usando um filtro de novidade. Revista Brasileira de Engenharia, 1997.

FAN, C.; ZOU, L.; WANG, Y. Digital image processing techniques applied in cable insulation parameters measurement, of theln: IEEE INTERNATIONAL CONFERENCE ON AUTOMATION AND LOGISTICS QINGDAO. Proceedings... China, September 2008.

GLENN, E. K.; KIRKLAND L. V. Infrared laser imaging for circuit board and ic failure detection, IEEE, 2003.

GONZALES, R. C. Digital image processing. 2. ed. Prentice Hall, 2002. 793p.

IRIANTO, D. On the in-process inspection and correction facilities. International journal of quality e reliability management. v.12, n.9, p.110-22, 1995.

JURAN, J. M. Controle da qualidade Handbook. 9. ed. São Paulo: Makron books, 1993.

KASSAB, Randa e ALEXANDRE, Frédéric. Incremental data-driven learning of a novelty detectionmodel for one-class classification with application to highdimensional noisy data. Mach Learn, v. 74, p. 191-234, 2009.

KOHONEN, T. e OJA, E. Fast adaptive formation of orthogonalizing filters and associative memory in recurrent networks of neuron-like elements. Biological Cybernetics, v.21, p.85-95. 1976.

MÄENTEKA, S. Manufactoring failure rate. Definition \& Formulas. s. I.: s. ed., 2008

MARODIN, G. A., ECKERT, C. P. Avançando na implantação da logística interna lean: dificuldades e resultados alcançados no caso de uma empresa montadora de veículos. Revista Produção Online. Florianópolis, v.12, n. 2, p. 455-479, abr./jun. 2012.

ORTH, A. Desenvolvimento e implementação de um sistema de reconhecimento automático de peças mecânicas em uma célula flexível de manufatura. Projeto RAP. Laboratório de Automação Industrial, UFSC. CONGRESSO DA SOCIEDADE BRASILEIRA DE COMPUTAÇÃO, SBC 1998. Disponível em: <http://www.lcmi.ufsc/ orth/rap/rap.html>.

PENROSE, R. A generalized inverse for matrices. Proceedings of the Cambridge Philosophical Society, v. 52, p. 406-13, 1955.

PÉREZ, M. A. J. Arquitetura de redes neurais: uma aplicação a memórias associativas. Tese (Mestrado em Engenharia Elétrica)- Universidade Estadual de Campinas, 1991.

PULKKINEN, L. Improving the usability of manufactoring failure data. Dissertação (Mestrado)- Universidade de Oulo, 2005. 
ROBLES Jr, A.; BONELLI, V. Gestão da qualidade e do meio ambiente: enfoque econômico, financeiro e patrimonial. São Paulo: Atlas, 2008.

RUDEK, M.; COELHO, L. S.; CANCIGLIERI JUNIOR, O. Visão computacional aplicada a sistemas produtivos: fundamentos e estudo de caso. In: ENCONTRO NACIONAL DE ENGENHARIA DE PRODUÇÃO, 21,.2001, Salvador. Anais... Salvador, 2001.

SENA, F. J. Detecção automática do mycobacterium tuberculosis em imagens de microscopia convencional através da utilização de segmentação de cor e limiar global adaptativo. Dissertação (Mestrado em Engenharia Elétrica), Faculdade de Tecnologia, Universidade Federal do Amazonas, 2007.

SOARES, D.; Valle, R; Baldam, R.; Ragonezi, T. Inovação de processos: um estudo comparativo sobre sua implementação. Gestão Industrial, v.2, n.4, p.55-62, 2006.

SOUZA, D. V. S., NETO, J. F. K., ANZANELLO, M. J. Avaliação de desempenho da cadeia de suprimentos balizada por critérios de competitividade empresarial.

Revista Produção Online. Florianópolis, v.12, n. 3, p. 756-778, jul./set. 2012.

WERNKE, R. Gestão de custos: uma abordagem prática. São Paulo: Atlas, 2004.

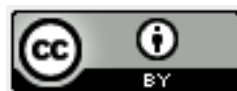

Artigo recebido em 16/08/2012 e aceito para publicação em 09/06/2013. 